\title{
Physical activity levels after low anterior resection for rectal cancer: one-year follow-up
}

Anne Asnong ${ }^{1 *}$, André D'Hoore ${ }^{2}$, Albert Wolthuis², Yves Van Molhem³ ${ }^{3}$ Bart Van Geluwe ${ }^{4}$, Annouschka Laenen ${ }^{5}$, Nele Devoogdt ${ }^{1,6}$, An De Groef ${ }^{1,7,8}$, Tessa De Vrieze ${ }^{1,9}$, Charlotte Van Calster ${ }^{1}$ and Inge Geraerts ${ }^{1}$

\begin{abstract}
Background: Overall survival rates after rectal cancer have increased. Therefore, functional outcomes rightly deserve more interest. The aims of this study were to assess progression in total, sports, occupational and household physical activity levels of rectal cancer survivors, from preoperatively to 12 months after surgery/stoma closure and to explore predictive factors.
\end{abstract}

Methods: Multi-center prospective study with 125 patients who underwent low anterior resection for rectal cancer. The Flemish Physical Activity Computerized Questionnaire was completed concerning all physical activity levels at baseline (past preoperative year) and at 1, 4,6 and 12 months after surgery/stoma closure. At these timepoints, questionnaires (LARS-/ COREFO-questionnaire) regarding bowel symptoms were also filled out. Results were analyzed using linear mixed models for repeated measures.

Results: Total physical activity levels up to 12 months remained significantly lower than preoperative. Occupational and sports physical activity levels remained significantly lower until 6 and 4 months postoperative, respectively. Predictive factors for decreased physical activity levels at a specific timepoint were: younger age and no stoma (total physical activity, 1 month), low/mid rectal tumor, no stoma, non-employed status (total, 4 months), higher COREFOscores (occupational, 4 months) and non-employed status (total, 12 months). At all timepoints, lower COREFO-scores were associated with higher total physical activity levels; male gender and lower educational levels with higher occupational levels; younger age, normal BMI, employed status and adjuvant therapy with higher sports levels; and female gender, lower educational level and unemployed status with higher household levels.

Conclusions: One year after rectal cancer treatment, total physical activity levels were still not recovered. Rectal cancer patients, especially those at risk for decreased physical activity levels and with major bowel complaints, should be identified and guided to increase their activities.

Trial registration: This trial has been registered at Netherlands Trial Register (NTR6383, 23/01/2017).

Keywords: Physical activity, Activities of daily living, Rectal neoplasms, Low anterior resection, Bowel symptoms, Predictive factors, Questionnaire

*Correspondence: anne.asnong@kuleuven.be

1 Department of Rehabilitation Sciences, Research Group Rehabilitation in Internal Disorders, KU Leuven - University of Leuven, Leuven, Belgium Full list of author information is available at the end of the article

\section{Background}

Worldwide, colorectal cancer (CRC) is the second most common cancer in women and the third most common cancer in men [1]. Almost $40 \%$ of these tumors find their origin in the rectum [1]. A low anterior resection (LAR) - more specifically a nerve-sparing, total mesorectal excision (TME) - remains the standard of surgical care in 
treating rectal cancer $(\mathrm{RC})$. Due to improved treatment plans (including (neo) adjuvant radio- and/or chemotherapy), local recurrence rates are low [2] and overall survival have improved, albeit not without debilitating functional consequences. Between 60 and $90 \%$ of RC survivors experience the 'Low Anterior Resection Syndrome' (LARS) [3-5]. Recently, a consensus definition of LARS was formulated, which incorporates symptoms as well as consequences [6]. Following this definition, LARS is defined as the presence of at least one of the following symptoms: variable and unpredictable bowel function, altered stool consistency, increased stool frequency, repeated painful stools, emptying difficulties, urgency, incontinence or soiling. In order to classify these bowel symptoms as LARS, the presence of one or more of these symptoms should lead to an impact on predefined consequences, such as toilet dependence, dissatisfaction with bowels or mental and emotional wellbeing [6]. Therefore, greater emphasis on functional outcome improvement is necessary.

The impact of cancer treatment and its consequences on physical activity (PA) has been investigated in various studies [7-16]. PA concerns many different aspects: total, sports, occupational and household PA. PA levels are often investigated in the context of their capacity of reducing the risk of developing (C)RC. Results demonstrated that PA is associated with a reduced risk for colon cancer, but not for rectal cancer [9, 17]. Furthermore, most of these studies focused on only one of the aspects of PA and their interest was mainly targeting the effect of exercise interventions $[8,10,11]$. Higher PA levels were related to a better quality of life in $(C) R C$ cancer survivors $[7,8]$. However, to date, there are no studies describing the progression of the different aspects of PA during the first year after low anterior resection (LAR) in RC survivors. This is a major gap compared to other cancer populations [18-20].

Some patient-, treatment- and disease-related factors are associated with decreased PA levels after RC surgery. Lower levels of leisure-time PA were associated with older age, more years since surgery, lower educational level, lower income, and not having a partner [7]. Temporary stoma [21], neoadjuvant therapy [21], side-toend coloanal anastomosis [22] and lower tumor height [23] were proven to influence the development of major LARS (symptoms like incontinence, frequency, clustering or urgency). Emmertsen et al. [21] stated that major LARS could have a negative effect on health in general and thus also on PA in RC survivors. Therefore, the aforementioned factors could be hypothesized to also negatively affect PA.

Thus, the aims of this study were to assess progression in total, sports, occupational and household PA levels of RC survivors, from preoperatively to $1,4,6$ and 12 months after surgery/after stoma closure and to explore predictive factors for a decreased PA. We hypothesized that postoperative PA levels would not reach preoperative levels after treatment for rectal cancer and that the aforementioned predictive factors under investigation would have an effect on PA.

\section{Methods}

This trial was approved by the local Ethical Committee of the University Hospitals Leuven (main Ethical Committee, reference s59761) and a positive advice from the Ethical Committees of the OLV Hospital Aalst and the General Hospital Groeninge Kortrijk was obtained. The trial was registered at Netherlands Trial Register (NTR6383, 23/01/2017).

This multi-center prospective study was conducted from January 2017-February 2021. All participants were recruited in Belgium at University Hospitals Leuven, OLV Hospital Aalst or General Hospital Groeninge Kortrijk. Patients who had a LAR (TME) for RC were eligible, but were excluded if they: (1) had another type of surgery for CRC, (2) were incontinent (faeces) before surgery, (3) had neurological diseases, (4) already had previous pelvic surgery, previous pelvic radiation or LAR for non-cancer reasons. Patients were included one month following surgery (LAR)/stoma closure (in case of a temporary stoma).

After consent, patients were asked to fill out the three following questionnaires: 1) the Flemish Physical Activity Computerized Questionnaire [24] (FPACQ) regarding $\mathrm{PA}$ and concerning bowel symptoms, 2) the Low Anterior Resection Syndrome Score [25] (LARSquestionnaire) and 3) the ColoRectal Functional Outcome questionnaire (COREFO-questionnaire) [26]. The FPACQ is a reliable and valid questionnaire to evaluate all PA levels (total, occupational, sports and household) [24]. Test-retest intraclass correlations of the FPACQ were good to excellent for both (un)employed/retired men and women. Furthermore, the FPACQ was found to be valid by comparing questionnaire-outcomes with results from the RT3 accelerometer [24]. All metabolic equivalent of task (MET) values used to calculate the PA variables were determined using the Ainsworth compendium of activities [27]. An overview of questionnaire characteristics can be found in Table 1 and calculation of each aspect of the FPACQ is explained with an example in Table 2. The LARS-questionnaire [25, 28 ] and the COREFO-questionnaire [26] were proven to be reliable for the assessment of bowel symptoms in this patient group. Furthermore, construct validity and criterion validity have been previously evaluated for the LARS-questionnaire [25, 28-30] and the 
Table 1 Overview of questionnaire characteristics

\begin{tabular}{|c|c|c|c|c|}
\hline & Tool & Evaluation of & Description & SCORE \\
\hline Physical activity & FPACQ & $\begin{array}{l}\text { physical activity and sedentary } \\
\text { behavior during a usual week }\end{array}$ & $\begin{array}{l}\text { one-week period } \\
\text { domains: } \\
\text { - patient-related data } \\
\text { - data related to occupational } \\
\text { activities: } \\
\text { O occupational status ((un) } \\
\text { employed) } \\
\text { O working hours per week } \\
\text { O job intensity } \\
\text { O transport to the job } \\
\text { - sport activities ( } 3 \text { most fre- } \\
\text { quently performed sports): } \\
\text { O frequency } \\
\text { O duration } \\
\text { - household activities } \\
\text { O light } \\
\text { O moderate } \\
\text { O vigorous } \\
\text { - transport during leisure time } \\
\text { - sedentary activities (TV and } \\
\text { sleep) }\end{array}$ & $\begin{array}{l}\text { in MET-h/week: } \\
\text { - total physical activity } \\
\text { - occupational physical activity } \\
\text { - sports physical activity } \\
\text { - household physical activity }\end{array}$ \\
\hline \multirow[t]{2}{*}{ Bowel symptoms } & LARS-questionnaire & $\begin{array}{l}\text { Low Anterior Resection Syndrome } \\
\text { symptoms }\end{array}$ & $\begin{array}{l}\text { four-week period } \\
\text { five questions with weighted } \\
\text { score values }\end{array}$ & $\begin{array}{l}\text { LARS-categories: } \\
\text {-"no LARS" (0-20 points) } \\
\text { - "minor LARS" (21-29 points) } \\
\text {-"major LARS" (30-42 points) }\end{array}$ \\
\hline & COREFO-questionnaire & $\begin{array}{l}\text { functional outcome after colorec- } \\
\text { tal surgery }\end{array}$ & $\begin{array}{l}\text { two-week period } \\
27 \text { questions, score } 0-4 \text { for each } \\
\text { question }\end{array}$ & $\begin{array}{l}\text { between } 0 \text { and } 100 \text {, with a } \\
\text { higher score representing more } \\
\text { symptoms }\end{array}$ \\
\hline
\end{tabular}

Table 2 Calculation of total, occupational, sports and household PA levels

\begin{tabular}{|c|c|c|}
\hline Definition & EXAMPLE & FORMULA \\
\hline \multirow[t]{2}{*}{$\begin{array}{l}\text { occupational } \\
\text { PA level }\end{array}$} & $\begin{array}{l}\text { - A patient worked } 38 \mathrm{~h} / \text { week with } 20 \% \\
\text { light, } 70 \% \text { moderate and } 10 \% \text { vigorous } \\
\text { activities. }\end{array}$ & $\begin{array}{l}\text { - occupational: }(38 \mathrm{~h} / \text { week } \times 20 \% \times 2 \mathrm{MET})+(38 \mathrm{~h} / \text { week } \times 70 \% \times 3 \mathrm{MET})+(38 \mathrm{~h} / \text { week } \times \\
10 \% \times 4 \mathrm{MET})=110 \mathrm{MET} \text {-hours/week }\end{array}$ \\
\hline & - He drove $1.3 \mathrm{~h} /$ week for work by car. & $\begin{array}{l}\text { - activity level for transport for work: } \\
\text { 1.3 h/week } \times 1.5 \mathrm{MET}=2 \mathrm{MET} \text {-hours/week }\end{array}$ \\
\hline $\begin{array}{l}\text { sports } \\
\text { PA level }\end{array}$ & This patient performed two sports. & $\begin{array}{l}(2 \mathrm{~h} / \text { week } \times 5.5 \mathrm{MET})+(0.7 \mathrm{~h} / \text { week } \times 3.5 \mathrm{MET}) \\
=13 \mathrm{MET} \text {-hours } / \text { week }\end{array}$ \\
\hline $\begin{array}{l}\text { household } \\
\text { PA level }\end{array}$ & $\begin{array}{l}\text { He also performed } 10 \mathrm{~h} / \text { week light, } 4 \mathrm{~h} / \\
\text { week moderate and } 1.5 \mathrm{~h} / \text { week vigor- } \\
\text { ous household activities. }\end{array}$ & $\begin{array}{l}(10 \mathrm{~h} / \text { week } \times 2.5 \mathrm{MET})+(4 \mathrm{~h} / \text { week } \times 3.5 \mathrm{MET})+(1.5 \mathrm{~h} / \text { week } \times 4.5 \mathrm{MET}) \\
=46 \mathrm{MET} \text {-hours } / \text { week }\end{array}$ \\
\hline $\begin{array}{l}\text { total } \\
\text { PA level }\end{array}$ & & $\begin{array}{l}\text { occupational }+ \text { sports }+ \text { household PA levels }(\text { explained above })+\text { active transport in leisure } \\
\text { time }(1.0 \mathrm{~h} / \text { week } \times 4 \mathrm{MET})+\text { eating }(8.8 \mathrm{~h} / \text { week } \times 1.8 \mathrm{MET})+\text { sleeping }(49 \mathrm{~h} / \text { week } \times 0.9 \\
\mathrm{MET})+ \text { quiet leisure time }(47.7 \mathrm{~h} / \text { week } \times 1.5 \mathrm{MET}) \\
=307 \mathrm{MET} \text {-hours/week }\end{array}$ \\
\hline
\end{tabular}

Using the definition for a MET as the ratio of work metabolic rate to a standard resting metabolic rate of $1.0 \mathrm{kcal} / \mathrm{kg} / \mathrm{h}$, one MET is considered as the resting metabolic rate during quiet sitting

COREFO-questionnaire as well [26, 30]. All patients prospectively completed the questionnaires within 2-7 days postoperatively (concerning preoperative year) and at 1, 4, 6 and 12 months after LAR/stoma closure. Patients were contacted by telephone if no response was received. A member of the research team checked for completeness upon receival of the questionnaires.

\section{Predictive factors}

Patient-, disease- and treatment-related factors were prospectively collected. Patient-related factors were age, gender, body mass index (BMI), partner status, educational level and employment status. These factors were collected as part of the FPACQ. Disease-related factors included tumor height (obtained from patient 
records) and bowel symptoms, inferred from the LARS-score and COREFO-questionnaire. Treatmentrelated factors included type of reconstruction (straight coloanal anastomosis, side-to-end coloanal anastomosis, J-pouch), (neo)-adjuvant therapy and stoma and were obtained from patient records at one month after LAR/stoma closure.

\section{Statistical analysis}

Linear mixed models for repeated measures were used to evaluate the progression of continuous variables (total, occupational, sport and household activity levels) over time. Time was modelled as a categorical variable, whereas an unstructured covariance matrix is modelled to account for the correlation between repeated measurements. This approach has the advantage - compared to classical repeated measures ANOVA - that subjects with one or more missing measurements were still included in the analysis and that results were still valid when dropout was missing at random [31]. Therefore, measurements without baseline values, could be included. Similar models were used to analyze the effect of various predictors (patient-, disease- and treatment-related factors) on the PA level and its evolution over time (baseline, 1, 4, 6 and 12 months postoperative). These models include time, predictor and the time by predictor interaction. A logistic regression model for repeated measures, with unstructured covariance matrix, was used to evaluate longitudinal binary measures such as job status or practicing sports. The analysis of the occupational PA level was restricted to preoperatively employed patients and the sports PA level to patients practicing some sports preoperatively. Patients, who retired during follow-up, were only considered at the time points they were still employed.

Tukey-Kramer or Holm adjustment was used for multiple post hoc comparisons. Analyses have been performed using SAS software (version 9.4, SAS System for Windows), a $P$ value $<0.05$ was considered statistically significant.

\section{Results}

One hundred twenty-five patients were included. Concerning the PA level one year before surgery, 120 patients filled out the FPACQ. At 1, 4, 6 and 12 months, 121 (96.8\%), 113 (90.4\%), 105 (84.0\%) and $101(80.8 \%)$ patients filled out the questionnaire, respectively. Baseline characteristics can be found in Table 3.
Table 3 Baseline characteristics $(n=125)$ and bowel complaints

\begin{tabular}{|c|c|c|}
\hline \multirow[t]{2}{*}{ Variable } & \multicolumn{2}{|l|}{ Value } \\
\hline & $\begin{array}{l}\text { mean }(\mathrm{SD}) / \\
\text { median (IQR) }\end{array}$ & n (\%) \\
\hline Age, years, mean (SD) & $58.49(11.07)$ & \\
\hline$\leq 49$ years & & $23(18.40)$ \\
\hline $50-69$ years & & $82(65.60)$ \\
\hline$\geq 70$ years & & $20(16.00)$ \\
\hline \multicolumn{3}{|l|}{ Gender } \\
\hline Male & & $83(66.40)$ \\
\hline Female & & $42(33.60)$ \\
\hline BMI, kg/m², median (IQR) & $24.58(22.77-27.48)$ & \\
\hline$<25.0$ & & $69(55.20)$ \\
\hline $25.1-30.0$ & & $39(31.20)$ \\
\hline$>30.0$ & & $17(13.60)$ \\
\hline \multicolumn{3}{|l|}{ Partner } \\
\hline Yes & & $109(87.20)$ \\
\hline No & & $16(12.80)$ \\
\hline \multicolumn{3}{|l|}{ Educational level } \\
\hline Semi-/unskilled & & $72(57.60)$ \\
\hline Highly skilled & & $53(42.40)$ \\
\hline \multicolumn{3}{|l|}{ Employment status } \\
\hline Retired & & $54(43.20)$ \\
\hline Employed & & $61(48.80)$ \\
\hline Unemployed & & $10(8.00)$ \\
\hline \multicolumn{3}{|l|}{ Tumor height ${ }^{a}$} \\
\hline Low $(0-5 \mathrm{~cm})$ & & $67(53.60)$ \\
\hline $\operatorname{Mid}(6-10 \mathrm{~cm})$ & & $39(31.20)$ \\
\hline High $(11-15 \mathrm{~cm})$ & & $19(15.20)$ \\
\hline \multicolumn{3}{|l|}{ LARS-score $(n=124)$} \\
\hline No & & $81(66.39)$ \\
\hline Minor & & $20(16.39)$ \\
\hline Major & & $21(17.21)$ \\
\hline COREFO-score, median (IQR) $(n=122)$ & $5.77(1.92-12.50)$ & \\
\hline \multicolumn{3}{|l|}{ Type of reconstruction } \\
\hline Straight coloanal anastomosis & & $73(58.40)$ \\
\hline Side-to-end coloanal anastomosis & & $33(26.40)$ \\
\hline $\begin{array}{l}\text { Colon pouch-anal anastomosis/J- } \\
\text { pouch }\end{array}$ & & $19(15.20)$ \\
\hline \multicolumn{3}{|l|}{ Neoadjuvant therapy } \\
\hline No & & $41(32.80)$ \\
\hline Chemo- and/or radiotherapy & & $84(67.20)$ \\
\hline \multicolumn{3}{|l|}{ Adjuvant therapy } \\
\hline No & & $67(53.60)$ \\
\hline Chemotherapy & & $56(44.80)$ \\
\hline Chemoradiotherapy & & $2(1.60)$ \\
\hline \multicolumn{3}{|l|}{ Stoma (duration of 178 days $( \pm 108)$ ) } \\
\hline Yes & & $107(85.60)$ \\
\hline No & & $18(14.40)$ \\
\hline
\end{tabular}

a from the anal verge 
Table 4 Progression of PA levels over time

\begin{tabular}{|c|c|c|c|c|c|}
\hline $\mathrm{PA}$ & $\begin{array}{l}\text { Preoperative } \\
(N=120)\end{array}$ & $\begin{array}{l}1 \text { MONTH } \\
(N=121)\end{array}$ & $\begin{array}{l}4 \text { MONTHS } \\
(N=113)\end{array}$ & $\begin{array}{l}6 \text { MONTHS } \\
(N=105)\end{array}$ & $\begin{array}{l}12 \text { MONTHS } \\
(N=101)\end{array}$ \\
\hline \multicolumn{6}{|l|}{ Total PA: } \\
\hline Mean estimate, MET-h/week & 274.21 & 251.00 & 260.70 & 263.25 & 264.74 \\
\hline $95 \% \mathrm{Cl}$ & $267.29-281.12$ & $246.32-255.67$ & $254.77-266.63$ & $255.37-271.13$ & $258.21-271.27$ \\
\hline$P$ & & $<.001^{*}$ & $<.001^{*}$ & $0.048^{*}$ & $0.046^{*}$ \\
\hline \multicolumn{6}{|l|}{ Occupational PA: } \\
\hline Mean estimate, MET-h/week & 106.22 & 79.35 & 84.57 & 89.53 & 95.23 \\
\hline $95 \% \mathrm{Cl}$ & $97.17-115.27$ & $59.01-99.68$ & $72.58-96.56$ & $78.51-100.55$ & $84.77-105.69$ \\
\hline$P$ & & $0.030^{*}$ & $0.001^{*}$ & $0.017^{*}$ & 0.058 \\
\hline \multicolumn{6}{|l|}{ Sports PA: } \\
\hline Mean estimate, MET-h/week & 17.18 & 3.98 & 8.42 & 11.71 & 11.58 \\
\hline $95 \% \mathrm{Cl}$ & $13.42-21.91$ & $2.48-6.13$ & $5.57-12.49$ & $7.95-17.05$ & $7.64-17.32$ \\
\hline$P$ & & $<.001^{*}$ & $0.002^{*}$ & 0.259 & 0.277 \\
\hline \multicolumn{6}{|l|}{ Household PA: } \\
\hline Mean estimate, MET-h/week & 34.45 & 30.63 & 32.40 & 29.35 & 33.14 \\
\hline $95 \% \mathrm{Cl}$ & $30.14-38.77$ & $25.86-35.40$ & $28.17-36.62$ & $25.61-33.09$ & $28.60-37.69$ \\
\hline$P$ & & 0.476 & 0.853 & 0.075 & 0.972 \\
\hline
\end{tabular}

$P$ value of pairwise differences between preoperative and the particular point in time

* $P$ value $<0.05$

\section{Progression of PA}

An overview of the results of the progression of PA is provided in Table 4. The total PA levels decreased by 8.5\% (from 274.21 MET-h/week preoperatively to $251.00 \mathrm{MET}-\mathrm{h} /$ week) at one month after LAR (or stoma closure). At 4, 6 and 12 months after LAR/stoma closure, total PA levels were respectively $4.9,4.0$ and $3.5 \%$ lower than baseline (Fig. 1).
A similar trend was found for occupational and sports PA levels. Patients who were employed before LAR $(n=60)$ spent $25 \%$ less MET-hours on occupational activities at 1 month. At 4, 6 and 12 months, a decrease of respectively 20,16 and $10 \%$ in occupational PA levels was recorded (Fig. 2). Of the non-retired patients $(n=71)$, $60(85 \%)$ were employed before surgery. At 1, 4, 6 and 12 months, $31,42,48$ and $52 \%$ had resumed their professional activities.

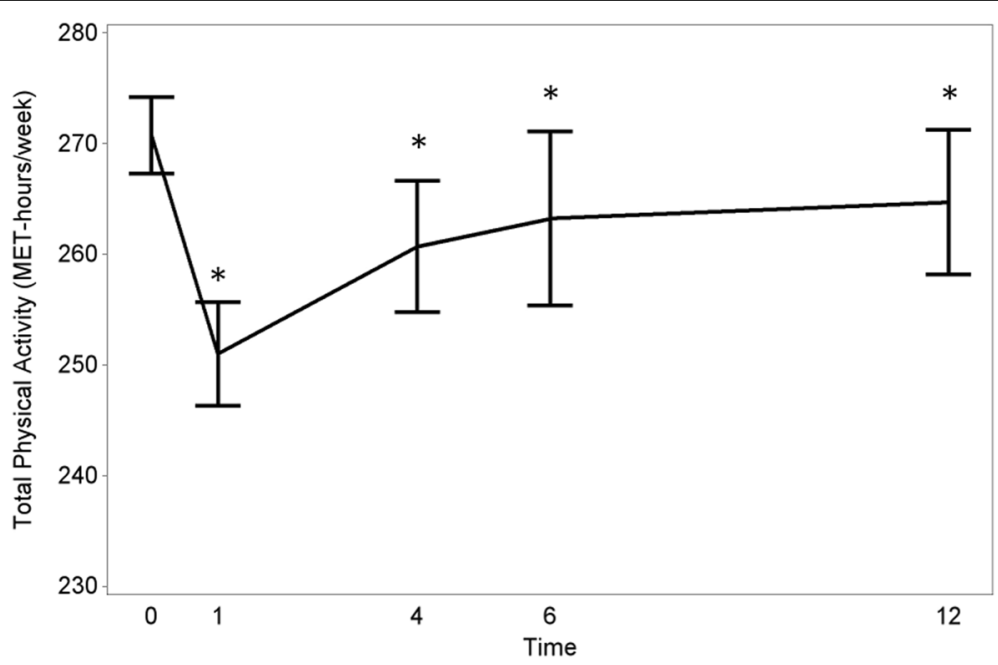

Fig. 1 Progression of the total PA (MET-hours/week) levels of RC patients from the preoperative stage to 12 months after surgery/stoma 


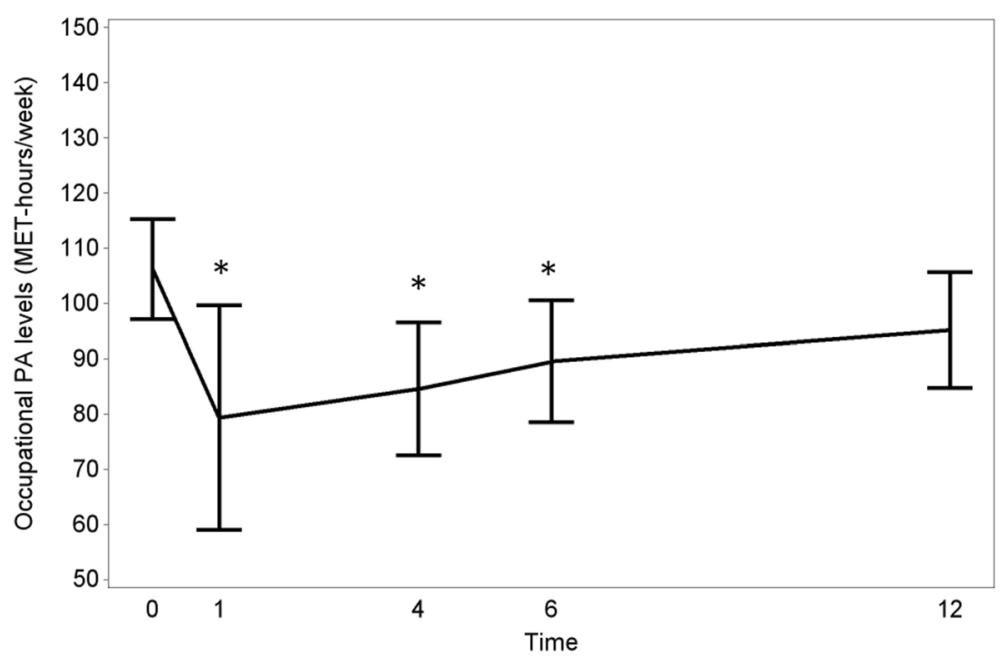

Fig. 2 Progression of the occupational PA (MET-hours/week) levels of RC patients from the preoperative stage to 12 months after surgery/stoma

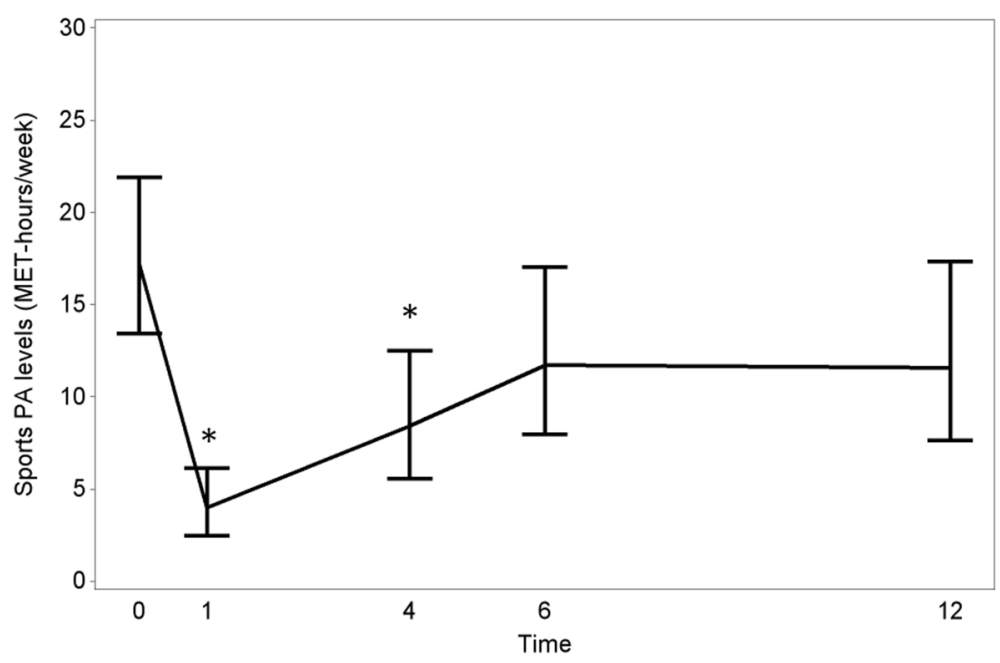

Fig. 3 Progression of the sports PA (MET-hours/week) levels of RC patients from the preoperative stage to 12 months after surgery/stoma

In patients that were performing sports before surgery $(n=70)$, the sports PA level reduced with $77 \%$ at one month postoperatively (Fig. 3). Decreases of 51, 32 and $33 \%$ were noted for 4,6 and 12 months postoperative, respectively. Of the preoperatively sport-active patients $(\mathrm{n}=70), 59,77,82$ and $80 \%$ were practicing sport activities at 1, 4, 6 and 12 months. From patients that were not sport-active before surgery, $31 \%$ did practice some sport activity at 12 months.

Postoperative household PA levels remained relatively stable compared to preoperative levels and no significant results were found.

\section{Predictive factors for progression of PA levels}

Overall, the total PA level was not significantly influenced by age, tumor height or stoma at the different timepoints. However, younger patients had a greater decrease in total PA level than older patients $(p=0.007$ and $p=0.002$ ) at 1 month after surgery/stoma closure (Fig. 4A). Additionally, patients with a low $(p=0.013)$ or mid $(p=0.005)$ rectal tumor, had a larger decrease in total PA level at 4 months than patients with a high rectal tumor (Fig. 4B) and patients with a stoma had a stronger decrease in total PA level at $1(p=0.004)$ and 4 months $(p=0.019)$ (Fig. 4C). Furthermore, total PA levels were 


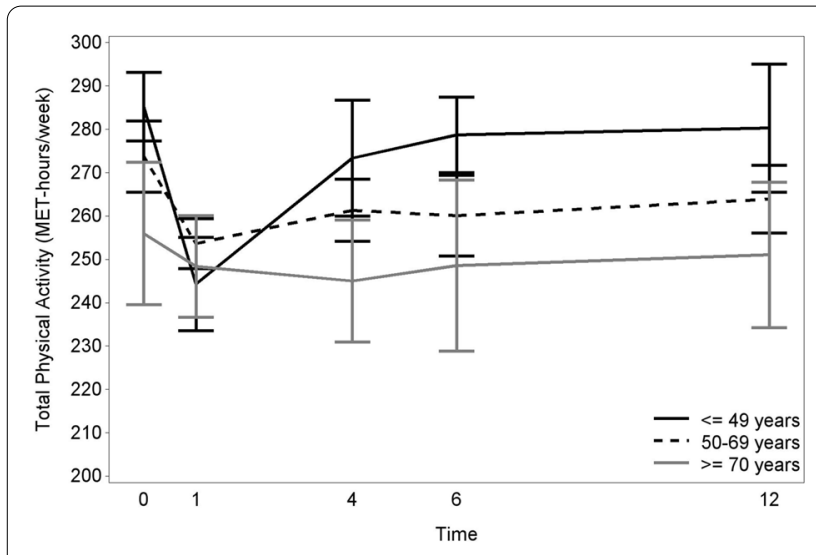

A

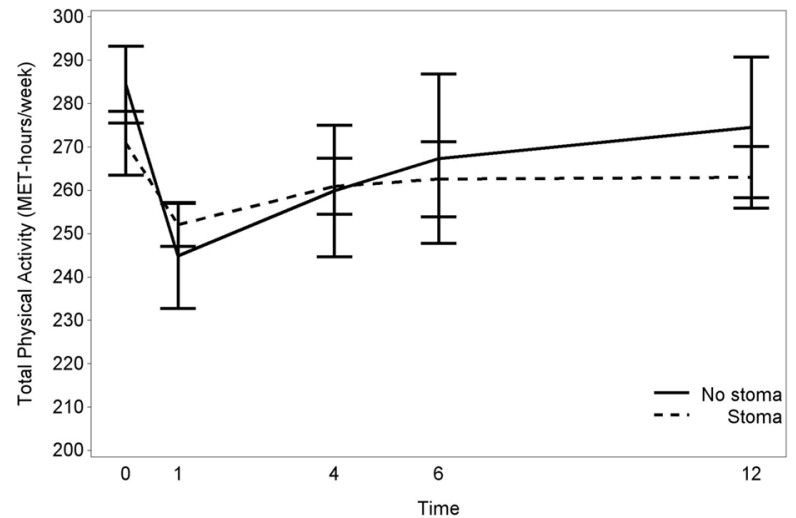

C

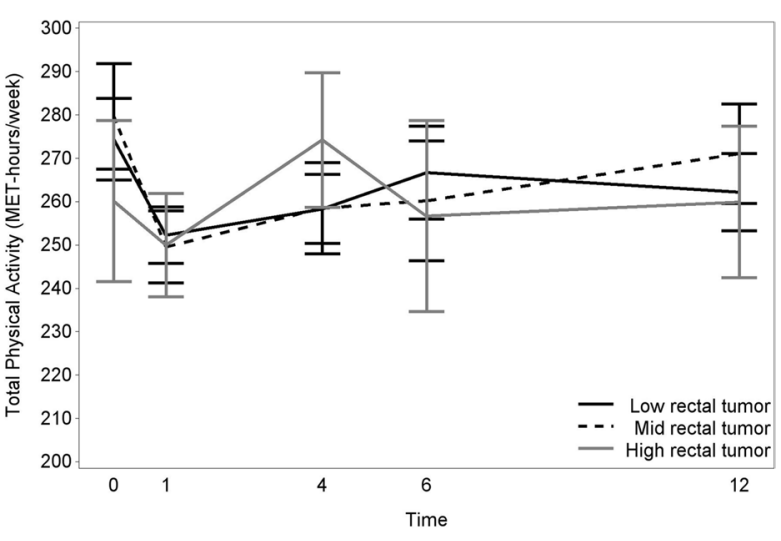

B

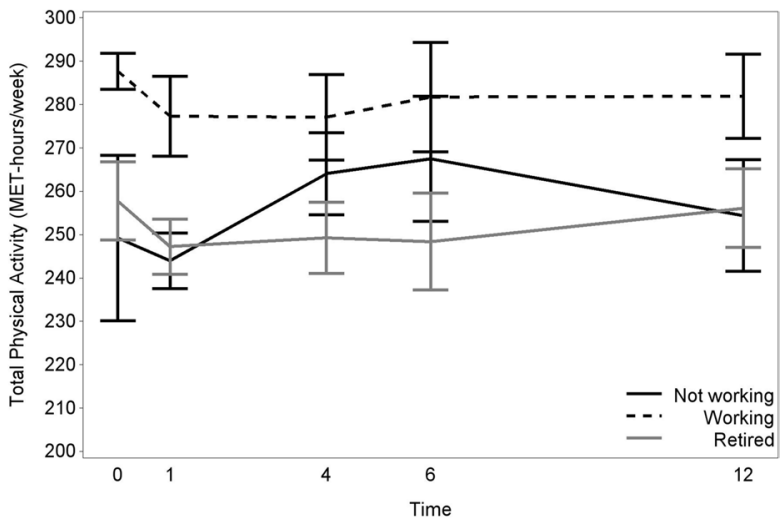

D

Fig. 4 Predictive factors for total PA levels from the preoperative stage to 12 months after surgery/stoma closure

higher for working patients compared to retired patients at all points in time $(p<0.001$ at 1 month to $p=0.014$ at 12 months). Total PA levels for working patients compared to non-working patients (non-employed and sick/ disabled patients) were only significantly higher at baseline $(\mathrm{p}=0.004), 4(\mathrm{p}<0.001)$ and $12(p=0.031)$ months postoperatively/after stoma closure (Fig. 4D). Consequently, the effect of bowel symptoms (COREFO-scores) on total PA level was not different at the various time points, indicating a general effect. In particular, higher COREFO-scores were shown to be associated with lower total PA levels $(p=0.002)$. For every increase of one point on the COREFO-score, the total PA decreased with 0.24 MET-h/week.

The occupational PA level of male patients $(p=0.001)$ and patients with a lower educational level $(p=0.037)$ is significantly higher than for females or patients with a higher educational level at all timepoints. Furthermore, the amount of bowel symptoms had a significant effect on the absolute level of occupational PA only at 4 months. For every increase of one point on the
COREFO-score at 4 months $(p=0.040)$ a patient was 0.9 MET-h/week less physically active (Fig. 5).

Regarding household PA levels, females $(p=0.003)$, lower educated patients $(p<0.001)$ and unemployed patients $(p=0.035)$ had significantly higher household PA levels than males, higher educated patients and employed patients, at every time point $(1,4,6$ and 12 months after LAR/stoma closure).

Concerning sports PA levels, younger patients (age $<50$ years; $\mathrm{p}=0.040$ ), patients with a normal BMI $\left(\leq 25 \mathrm{~kg} / \mathrm{m}^{2} ; p=0.001\right)$, employed patients $(p=0.013)$ and patients who underwent adjuvant therapy $(p=0.026)$ showed higher activity levels than older (age $50-70$ years), overweight $\left(25-30 \mathrm{~kg} / \mathrm{m}^{2}\right)$, non-employed patients or patients without adjuvant therapy, at every timepoint (1, 4, 6 and 12 months after LAR/stoma closure).

All patient-, disease-, and treatment-related factors (cfr. Methods section) were investigated for all aspects of PA. Due to the multitude of data, only significant predictors were discussed. 


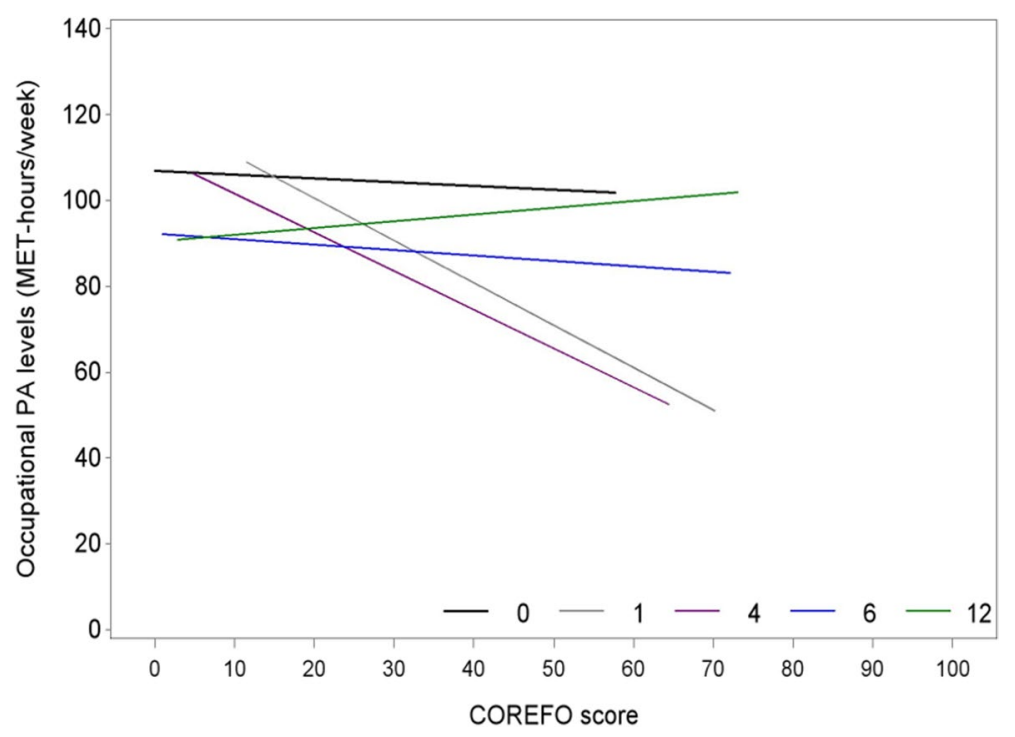

Fig. 5 Predictive factor for the progression of occupational PA levels from the preoperative stage to 12 months after surgery/stoma closure

\section{Discussion}

In this study, a decrease of $8.5 \%$ of the total PA level was found one month after LAR/stoma closure for RC. This decrease remained significantly lower up to one year after surgery/stoma closure, emphasizing the impact of the RC treatment on patients' PA. In general, literature in the context of RC and its association with PA after surgery is very scarce and most of the literature on functional consequences views $\mathrm{RC}$ and CRC survivors as one group. The same applies for rehabilitation programs in $\mathrm{RC}$ and CRC survivors. A recent systematic review of Balhareth et al. [32] showed that PA has been determined to positively impact the quality of life after CRC, but additionally showed also a lack of consensus on guidelines and conclusive evidence on the content and form of said rehabilitation programs.

To the best of our knowledge, no previous studies investigated the evolution of PA during the first year after LAR/stoma closure in RC patients. Nonetheless, PA was investigated in relation to health-related quality of life (HRQOL) in long-term RC survivors ( $\geq 5$ years) [7]. Other studies focused on the effects of (pre) rehabilitation programs for RC patients, in which possible positive effects on physical fitness $[10,11]$ and tumor regression [10] were highlighted. Additionally, most studies only focused on one aspect of PA. The decrease in total, as well as occupational and sports PA levels in our study can be explained by the fact that approximately half of the patients underwent adjuvant therapy after surgery, which has previously been found to be associated with declined exercise levels in CRC patients [12,13]. For occupational PA levels, the decrease up to 6 months is in line with previous research stating that work ability was decreased at 3 and 6 months after curative treatment for RC and return to work delayed [33, 34]. For household PA levels, no significant decreases were found in the postoperative progression of RC survivors.

Regarding predictive factors in the present study, the total PA level of younger patients (age $<50$ years), patients with a low/mid rectal tumor and patients with a stoma did not significantly differ from respectively older patients, patients with a high rectal tumor or patients without a stoma at the different timepoints. However, being younger was a predictive factor for a decreased total PA at one month. No previous research was found on predictive factors for total PA after RC. Secondly, patients without a stoma had a significantly greater decrease at one and four months after LAR, compared to baseline. Hence, it should be mentioned that patients without a stoma were included one month after their major surgery (LAR), while patients with a stoma were included at one month after stoma closure, i.e. after a longer timeframe (on average 178 days) since their LAR. Inclusion of patients at these specific timepoints was chosen because of the common interest in the impact of LAR on bowel function. Firstly, previous research has shown that LARS usually manifests in a period of one month after transit recovery [35]. Secondly, the interval from surgery to stoma closure was not associated with LARS [36]. Consequently, including patients only based on time after LAR would have prevented conclusions regarding the influence of bowel dysfunction on PA. Previous work has shown that stoma-related challenges (pouch leakages, skin irritation, risk of hernia, 
self-consciousness...) have a negative impact on patients' engagement in PA $[14,15]$. The lower total PA levels from 6 months onwards in patients who had a stoma could therefore be partially explained by persisting diminished PA due to the previous challenges, even after stoma closure. The significant decrease in total PA early after LAR patients without a stoma, might be explained by the influence of adjuvant therapy [12]. Furthermore, an interaction effect was found between tumor height and time, although this might be due to an inexplicable spike in the total PA at 4 months, in survivors with a high tumor. No literature was found regarding the predictive value of tumor height on PA levels. Concerning employment status, a significant interaction was found as well; probably due to an increase in total PA at 4 and 6 months in RC survivors who were not working due to unemployment or sickness/disability. This increase might be explained by a within-person change in employment status in patients who worked preoperatively. Bowel complaints could have forced employees to stay at home, as was stated in previous long-term research [34]. While they were not working at follow-up, their previous activity levels might have remained consistent. Lastly, higher COREFO-scores were correlated with lower total PA overall. Consequently, higher COREFO-scores were also predictive for lower occupational PA levels at 4 months after LAR/stoma closure. This was confirmed in previous research regarding the link between major LARS and the (in) ability to work [21] as well as long-term findings [34]. Furthermore, females and higher educated patients had generally lower levels of occupational PA overall. Lynch et al. [13] formerly confirmed this for PA in general after CRC.

For household PA levels, a higher educational level was also associated with lower PA, analogous to the results mentioned for occupational PA. For gender, however, being male was predictive for lower household PA levels, which might be linked to stereotypical gender roles concerning household work.

For sports PA levels, older age, being overweight or being unemployed/sick/disabled were predictive for generally lower PA levels after RC, which was in line with previous research stating that younger RC survivors reported more leisure-time PA [7] and increasing weight was associated with physical inactivity in cancer survivors in general [16]. No previous research was found on the predictive value of employment status.

The present study has many strengths. This is the first study to investigate the progression of all aspects of PA (total, occupational, sports and household). Patients were assessed before surgery regarding PA over the past year and at fixed time intervals after surgery/stoma closure up to 12 months. The return rate of the FPACQ was very high (81-96\% at the various timepoints). Furthermore, this study is unique in finding a predictor of return to PA in bowel symptoms after LAR for rectal cancer. In particular, the majority of patients filled in the LARS(80-99\%) and COREFO- (82-98\%) questionnaire at the various timepoints. All patients were operated in highvolume hospitals by very experienced surgeons, which enables generalization of the results. A limitation of the present study was that the FPACQ was proven to be reliable and valid in healthy adults but not specifically in RC patients. Furthermore, notwithstanding the validity and reliability, a weakness lies in using the FPACQ for the evaluation of PA- a questionnaire - which remains a subjective measurement method. Lastly, the results in this study should be interpreted with care given the multitude of models and $P$ values.

\section{Conclusion}

This is the first study to investigate the progression of PA as a whole (total, occupational, sports and household PA levels) after RC treatment, to find predictive factors for a decrease in PA after LAR for RC and to assess the impact of bowel symptoms on PA. All aspects of PA, except household PA, decreased significantly until 4 months after surgery/stoma closure. Occupational PA and total PA decreased even until respectively 6 and 12 months. Predictive factors for decreased PA levels at a specific timepoint were: younger age and no stoma (total PA, 1 month), low/mid rectal tumor, no stoma, non-employed status (total PA, 4months), higher COREFO-scores (occupational PA, 4 months) and non-employed status (total PA, 12 months). Furthermore, at all timepoints, lower COREFO-scores were associated with higher total PA levels; male gender and lower educational levels with higher occupational levels; younger age, normal BMI, employed status and adjuvant therapy with higher sports levels; and female gender, lower educational level and unemployed status with higher household levels. RC patients, especially those at risk for decreased PA levels and those with major bowel complaints, should be well guided to minimalize the decrease in PA levels and regain preoperative levels as soon as possible.

\section{Abbreviations \\ BMI: Body mass index; CRC: Colorectal cancer; COREFO: ColoRectal Functional Outcome questionnaire; FPACQ: Flemish Physical Activity Computerized \\ Questionnaire; LAR: Low anterior resection; LARS: Low Anterior Resection Syndrome; LARS-questionnaire: Low Anterior Resection Syndrome Score; MET: Metabolic equivalent of task; PA: Physical activity; RC: Rectal cancer; TME: Total mesorectal excision.}

\section{Acknowledgements}

The authors are grateful to the trial participants and would like to thank all participating centers and collaborating staff of this trial for their contributions on data acquisition. 


\begin{abstract}
Authors' contributions
AA: acquisition/analysis/interpretation of data, drafting of the work, critically revising of the work, final approval, agreement to be accountable, project management. ADH: conception/design of the work, acquisition/analysis/ interpretation of data, drafting of the work, critically revising of the work, final approval, agreement to be accountable, project management, fund procurement, consultation/supervision. AW: interpretation of data, critically revising of the work, final approval, agreement to be accountable. YVM: interpretation of data, critically revising of the work, final approval, agreement to be accountable. BVG: interpretation of data, critically revising of the work, final approval, agreement to be accountable. AL: analysis/interpretation of data, critically revising of the work, final approval, agreement to be accountable. ND: analysis/interpretation of data, drafting of the work, critically revising of the work, final approval, agreement to be accountable. ADG: interpretation of data, drafting of the work, critically revising of the work, final approval, agreement to be accountable. TDV: interpretation of data, critically revising of the work, final approval, agreement to be accountable. CVC: interpretation of data, critically revising of the work, final approval, agreement to be accountable. IG: conception/design of the work, acquisition/analysis/interpretation of data, drafting of the work, critically revising of the work, final approval, agreement to be accountable, project management, fund procurement, consultation/ supervision.
\end{abstract}

\section{Funding}

This clinical trial is supported by a grant of the Research Foundation - Flanders (FWO-TBM) (T000216N). Fonds Wetenschappelijk Onderzoek - Vlaanderen, Egmontstraat 5, 1000 Brussel. The funder of the study had no role in study design, data collection, data analysis, data interpretation, or writing of the report.

\section{Availability of data and materials}

The data that support the findings of this study are available from the corresponding author (anne.asnong@kuleuven.be) upon reasonable request.

\section{Declarations}

\section{Ethics approval and consent to participate}

This research was performed in accordance with the Declaration of Helsinki. Approval for this trial was granted by the local Ethical Committee of the University Hospitals Leuven (main Ethical Committee, s59761) and additionally a positive advice from the other centers (OLV Hospital Aalst and General Hospital Groeninge Kortrijk) was obtained. Patients signed an informed consent form.

\section{Consent for publication}

Not applicable.

\section{Competing interests}

The authors declare that they have no competing interests.

\section{Author details}

'Department of Rehabilitation Sciences, Research Group Rehabilitation in Internal Disorders, KU Leuven - University of Leuven, Leuven, Belgium. ${ }^{2}$ Department of Abdominal Surgery, University Hospitals Leuven and KU Leuven - University of Leuven, Leuven, Belgium. ${ }^{3}$ Department of Abdominal Surgery, OLV Hospitals Aalst/Asse/Ninove, Aalst, Belgium. ${ }^{4}$ Department of Abdominal Surgery, University Hospitals, Leuven, Belgium. ${ }^{5}$ Interuniversity Centre for Biostatistics and Statistical Bioinformatics, KU Leuven and Hasselt University, Leuven, Belgium. ${ }^{6}$ Center for lymphedema, University Hospitals Leuven, Leuven, Belgium. ' Department of Rehabilitation Sciences, University of Antwerp, Antwerp, Belgium. ${ }^{8}$ International Research Group Pain in Motion, Brussels, Belgium. ${ }^{9}$ Department of Rehabilitation Sciences and Physiotherapy, MOVANT, University of Antwerp, Antwerp, Belgium.

Received: 26 August 2021 Accepted: 17 November 2021

Published online: 13 December 2021

\section{References}

1. Ferlay J EM, Lam F, Colombet M, Mery L, Piñeros M, Znaor A, Soerjomataram I, Bray F. Global Cancer observatory: Cancer today. https://gco.iarc.fr/ today. Accessed 5 Dec 2019.

2. Borstlap WAA, Deijen $C L$, den Dulk $M$, et al. Benchmarking recent national practice in rectal cancer treatment with landmark randomized controlled trials. Color Dis. 2017;19(6):0219-31.

3. Ridolfi TJ, Berger N, Ludwig KA. Low anterior resection syndrome: current management and future directions. Clin Colon Rectal Surg. 2016;29(3):239-45.

4. Chen TY, Emmertsen KJ, Laurberg S. Bowel dysfunction after rectal cancer treatment: a study comparing the specialist's versus patient's perspective. BMJ Open. 2014;4(1):e003374.

5. Bryant CL, Lunniss PJ, Knowles $\mathrm{CH}$, Thaha MA, Chan CL. Anterior resection syndrome. Lancet Oncol. 2012;13(9):e403-8.

6. Keane C, Fearnhead NS, Bordeianou L, et al. International consensus definition of low anterior resection syndrome. Color Dis. 2020;22(3):331-41.

7. Krouse RS, Wendel CS, Garcia DO, et al. Physical activity, bowel function, and quality of life among rectal cancer survivors. Qual Life Res. 2017:26(11):3131-42.

8. Eyl RE, Xie K, Koch-Gallenkamp L, Brenner H, Arndt V. Quality of life and physical activity in long-term ( $>/=5$ years post-diagnosis) colorectal cancer survivors - systematic review. Health Qual Life Outcomes. 2018;16(1):112.

9. Wolin KY, Tuchman H. Physical activity and gastrointestinal cancer prevention. Recent Results Cancer Res. 2011;186:73-100.

10. West MA, Astin R, Moyses HE, et al. Exercise prehabilitation may lead to augmented tumor regression following neoadjuvant chemoradiotherapy in locally advanced rectal cancer. Acta Oncol. 2019:58(5):588-95.

11. Moug SJ, Mutrie N, Barry SJE, et al. Prehabilitation is feasible in patients with rectal cancer undergoing neoadjuvant chemoradiotherapy and may minimize physical deterioration: results from the REx trial. Color Dis. 2019;21(5):548-62.

12. Peddle CJ, Au H-J, Courneya KS. Associations between exercise, quality of life, and fatigue in colorectal cancer survivors. Dis Colon Rectum. 2008;51(8):1242.

13. Lynch BM, Cerin E, Newman B, Owen N. Physical activity, activity change, and their correlates in a population-based sample of colorectal cancer survivors. Ann Behav Med. 2007;34(2):135-43.

14. Saunders S, Brunet J. A qualitative study exploring what it takes to be physically active with a stoma after surgery for rectal cancer. Support Care Cancer. 2019;27(4):1481-9.

15. Neuman HB, Park J, Fuzesi S, Temple LK. Rectal cancer patients' quality of life with a temporary stoma: shifting perspectives. Dis Colon Rectum. 2012;55(11):1117-24.

16. Gjerset GM, Fossa SD, Courneya KS, Skovlund E, Thorsen L. Exercise behavior in cancer survivors and associated factors. J Cancer Surviv. 2011;5(1):35-43.

17. Murphy N, Ward HA, Jenab M, et al. Heterogeneity of colorectal Cancer risk factors by anatomical subsite in 10 European countries: a multinational cohort study. Clin Gastroenterol Hepatol. 2019;17(7):1323-31 e1326.

18. Devoogdt N, Van Kampen M, Geraerts I, et al. Physical activity levels after treatment for breast cancer: one-year follow-up. Breast Cancer Res Treat. 2010;123(2):417-25.

19. Geraerts I, Van Poppel H, Devoogdt N, Laenen A, De Groef A, Van Kampen M. Progression and predictors of physical activity levels after radical prostatectomy. BJU Int. 2014;114(2):185-92.

20. De Groef A, Geraerts I, Demeyer H, et al. Physical activity levels after treatment for breast cancer: two-year follow-up. Breast. 2018;40:23-8.

21. Emmertsen KJ, Laurberg $S$, Jess $P$, et al. Impact of bowel dysfunction on quality of life after sphincter-preserving resection for rectal cancer. Br J Surg. 2013;100(10):1377-87.

22. Parc $Y$, Ruppert $R$, Fuerst $A$, et al. Better function with a colonic J-pouch or a side-to-end anastomosis?: a randomized controlled trial to compare the complications, functional outcome, and quality of life in patients with low rectal cancer after a J-pouch or a side-to-end anastomosis. Ann Surg. 2019;269(5):815-26.

23. Wells Cl, Vather R, Chu MJ, Robertson JP, Bissett IP. Anterior resection syndrome--a risk factor analysis. J Gastrointest Surg. 2015;19(2):350-9. 
24. Matton L, Wijndaele K, Duvigneaud N, et al. Reliability and validity of the Flemish physical activity computerized questionnaire in adults. Res $Q$ Exerc Sport. 2007;78(4):293-306.

25. Emmertsen KJ, Laurberg S. Low anterior resection syndrome score: development and validation of a symptom-based scoring system for bowel dysfunction after low anterior resection for rectal cancer. Ann Surg. 2012;255(5):922-8.

26. Bakx R, Sprangers MA, Oort FJ, et al. Development and validation of a colorectal functional outcome questionnaire. Int J Color Dis. 2005;20(2):126-36.

27. Ainsworth BE, Haskell WL, Whitt MC, et al. Compendium of physical activities: an update of activity codes and MET intensities. Med Sci Sports Exerc. 2000;32(9 Suppl):S498-504.

28. Juul T, Ahlberg M, Biondo $S$, et al. International validation of the low anterior resection syndrome score. Ann Surg. 2014;259(4):728-34.

29. Hupkens BJP, Breukink SO, Olde Reuver Of Briel C, et al. Dutch validation of the low anterior resection syndrome score. Color Dis. 2018;20(10):881-7.

30. Liapi A, Mavrantonis C, Lazaridis P, et al. Validation and comparative assessment of low anterior resection syndrome questionnaires in Greek rectal cancer patients. Ann Gastroenterol. 2019;32(2):185-92.

31. Rubin DB. Inference and missing data. Biometrika. 1976;63(3):581-92.

32. Balhareth A, Aldossary MY, McNamara D. Impact of physical activity and diet on colorectal cancer survivors' quality of life: a systematic review. World J Surg Oncol. 2019;17(1):153.

33. Couwenberg AM, Intven MP, Gregorowitsch ML, Haaring C, van Grevenstein W, Verkooijen HM. Patient-reported work ability during the first two years after rectal cancer diagnosis. Dis Colon Rectum. 2020;63(5):578-87.

34. Garfinkle R, Ky A, Singh A, et al. Financial and occupational impact of low anterior resection syndrome in rectal cancer survivors. Color Dis. 2021.

35. Cura Pales CG, An S, Cruz JP, Kim K, Kim Y. Postoperative bowel function after anal sphincter-preserving rectal Cancer surgery: risks factors, diagnostic modalities, and management. Ann Coloproctol. 2019:35(4):160-6.

36. Jiménez-Rodríguez RM, Segura-Sampedro JJ, Rivero-Belenchón I, et al. Is the interval from surgery to ileostomy closure a risk factor for low anterior resection syndrome? Color Dis. 2017;19(5):485-90.

\section{Publisher's Note}

Springer Nature remains neutral with regard to jurisdictional claims in published maps and institutional affiliations.

Ready to submit your research? Choose BMC and benefit from:

- fast, convenient online submission

- thorough peer review by experienced researchers in your field

- rapid publication on acceptance

- support for research data, including large and complex data types

- gold Open Access which fosters wider collaboration and increased citations

- maximum visibility for your research: over $100 \mathrm{M}$ website views per year

At BMC, research is always in progress.

Learn more biomedcentral.com/submissions 